\title{
Gastro-intestinal Helminthic Infection in Herbivore Safari at Nandankanan Zoological Park
}

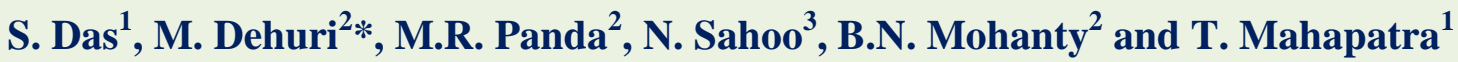 \\ ${ }^{1}$ Fisheries and Animal Resource Department, Government of Odisha, India \\ ${ }^{2}$ Department of Veterinary Parasitology, Orissa University of Agriculture and Technology, \\ Bhubaneswar, Odisha, India \\ ${ }^{3}$ Department of Preventive Medicine and In charge of Regional Centre for Wildlife Health, \\ Orissa University of Agriculture and Technology, Odisha, India
}

*Corresponding author

\section{A B S T R A C T}

\begin{tabular}{|l|}
\hline K e y w o r d s \\
Prevalence, \\
Gastrointestinal \\
parasites, \\
Herbivore, Odisha
\end{tabular}

\section{Introduction}

India is unique in having immense natural beauty and possessing a rich and diverse wildlife. Wild animals usually suffer from a wide range of various infectious agents like bacteria, viruses and parasites from time to time. A number of factors threaten the existence of wild animals in our country including wildlife diseases, in particular those arising from gastrointestinal parasites

\begin{abstract}
A study on the prevalence of gastrointestinal parasites of herbivores was undertaken in herbivore safari at Nandankanan Zoological Park, Odisha by collecting a total number of 509 faecal samples of 4 species which includes Spotted deer (Axis axis), Sambar (Cervus unicolor), Chausingha / four-horned antelope (Tetracerus quadricornis), and Barking deer (Muntiacus muntjac). 210 faecal samples were positive for helminthic infection indicating a total prevalence of $41.26 \%$. Coprological examination of the faecal samples revealed four types of helminths; Amphistomes (17\%), Strongyles (16\%), Strongyloides $\mathrm{sp}(2 \%)$ and Trichuris $\mathrm{sp}(1 \%)$. The prevalence of gastrointestinal helminths in Sambar, Spotted deer, Barking deer and Chausingha were found to be $68.8 \%, 42.61 \%, 17.12 \%$ and $16.28 \%$ respectively. Highest percentage of infection was observed during the rainy season $56.36 \%$ followed by winter $(43.75 \%)$ and summer $(23.81 \%)$.
\end{abstract}

(Thawait and Maiti, 2015). In nature, practically no animal is free from parasites. Inspite of quarantine measures, the parasitized animals when brought from wild to captivity, the new conditions of zoos are usually unfavorable for the animal but favorable to the parasites. Although the wild animals are usually infected with many species of parasites, yet massive death of epizootics because of them rarely occur (Banerjee $e t$ al., 2005). Epidemiological studies are essential to 
know the status and establish a data base of parasites in wild animals. Our study provides an overview of parasites present in the herbivore safari of Nandankanan Zoological Park.

\section{Materials and Methods}

This study was undertaken during August 2015 to July 2016 in Herbivore Safari at Nandankanan Zoological Park. A total of 509 faecal samples were collected randomly from 4 species of wild herbivore viz. Spotted deer (Axis axis), Sambar (Cervus unicolor), Chausingha or four-horned antelope (Tetracerus quadricornis), and Barking deer (Muntiacus muntjac). During the study period, 125, 230, 111 and 43 number of faecal samples were collected from Sambar, Spotted Deer, Barking deer and Chausingha respectively. Freshly dropped pooled faecal samples were collected in a clean, dry and individually labeled polythene bag and extreme care was taken to avoid extraneous contamination. The faecal samples were brought to the departmental laboratory for further investigation. Examination of faecal sample was done by Direct smear method, Sedimentation method, Floatation method using MgSO4 and identification was based on morphological features of the parasitic ova (Soulsby,1982). The counting of eggs was done by Stoll's dilution technique and Mc Master Technique. Faecal culture was done to know the species of the parasite infecting the herbivores. Statistical analysis were carried out by Statistical Package for Social Science (SPSS) version 22 using chi- square test.

\section{Results and Discussion}

Out of the total 509 faecal samples examined, 210 faecal samples were positive for helminthic infection while 299 were negative for presence of any parasitic ova indicating a total prevalence of $41.26 \%$. Faecal sample examination from 210 positive samples, showed $76.66 \%$ of samples having single infection while there was presence of mixed infection with two species of helminths in $23.33 \%$ of total positive samples. Coprological examination of the faecal samples revealed four types of helminths; Amphistomes (17\%), Strongyles (16\%), Strongyloides sp (2\%), Trichuris sp (1\%). The prevalence of gastrointestinal helminths in Sambar, Spotted deer, Barking deer and four horned antelope were found to be $68.8 \%$, $42.61 \%, 17.12 \%$ and $16.28 \%$ respectively.

In sambar, prevalence of amphistomes and strongyles were $45 \%$ and $18.4 \%$ respectively. There was no record of Strongyloides sp and Trichuris sp in Sambar, while mixed infection was seen in $5.6 \%$ of positive samples. Strongyles showed highest prevalence $(20.43 \%)$ in Spotted deer followed by amphistomes (11.3\%) and Trichuris sp. In Barking deer, the highest prevalence was recorded for ova of strongyles (8.1\%) followed by Strongyloides sp.(7.21\%) while amphistomes showed a mere prevalence of 0.9 $\%$ only. Mixed infection was seen in $0.9 \%$ of positive samples. In Chausingha, Amphistomes had a higher presence followed by Strongyles and Strongyloides sp (Figure 1).

Highest percentage of infection was observed during the rainy season $56.36 \%$, winter prevalence was $43.75 \%$ while during summer season there was only $23.81 \%$ (Table 1) with high significance in summer and significance during rainy season.

Overall prevalence of gastro-intestinal parasites in Herbivore Safari was 41.26\%, which is more or less similar to findings by Mohan and Coumarene (2007) from Puducherry; Sahoo et al., (2009) from the same zoo and Thawait and Maiti (2015) in Kanan Pandari Zoo of Bilaspur. A survey of gastro-intestinal parasites in herbivores by 
Gupta et al., 2011 around forests of Jabalpur as well as Rahman et al., (2014) at Dhaka National Zoological Garden detected a much higher prevalence $(70-80 \%)$. The variation could be due to difference in number and distribution of animals and variation in topography and climatic factors. A lower prevalence of $25.71 \%$ was reported by Singh et al., (2006) in wild herbivores at Mahendra Choudhury Zoological Park, Punjab. The conflicting report might be due to inclusion of more number of animal species (sixteen different herbivore species) and differences in geographical condition. The prevalence of mixed infection was seen in $22.33 \%$ of the total sample while Singh et al., 2006 from Punjab reported a higher rate, which could be due to differences in sample size and managemental condition. The most common infection during our survey was found to be of amphistomes $(41 \%)$ followed by Strongyles (39\%), Strongyloides sp (4\%) and Trichuris sp (3\%). In wild herbivores at Mudumalai Wildlife Sanctuary, TamilNadu highest infection of Strongyles (41.7\%), followed by amphistomes (15.6\%) and Strongyloides sp. (11.5\%) has been reported by Mandal et al., (2002).

Table.1 Prevalence of gastro-intestinal helminthsin different seasons in Herbivore Safari

\begin{tabular}{|c|c|c|c|c|}
\hline $\begin{array}{c}\text { Name of the } \\
\text { Season }\end{array}$ & $\begin{array}{c}\text { No. of total } \\
\text { sample collected }\end{array}$ & $\begin{array}{c}\text { No. of Positive } \\
\text { samples }\end{array}$ & $\begin{array}{c}\text { No. of negative } \\
\text { samples }\end{array}$ & $\begin{array}{c}\text { Chi sqare test } \\
\text { (p value) }\end{array}$ \\
\hline Rainy & 165 & 93 & 72 & $0.02644^{*}$ \\
\hline Winter & 176 & 77 & 99 & 2.642 \\
\hline Summer & 168 & 40 & 128 & $0.0001516^{* *}$ \\
\hline Total & 509 & 210 & 299 & \\
\hline
\end{tabular}

Highly significant $* *(p<0.01)$; Significant $*(p<0.05)$; Non-significant $(p>0.05)$

Fig.1 Prevalence of gastro-intestinal helminths in different animals of herbivore safari

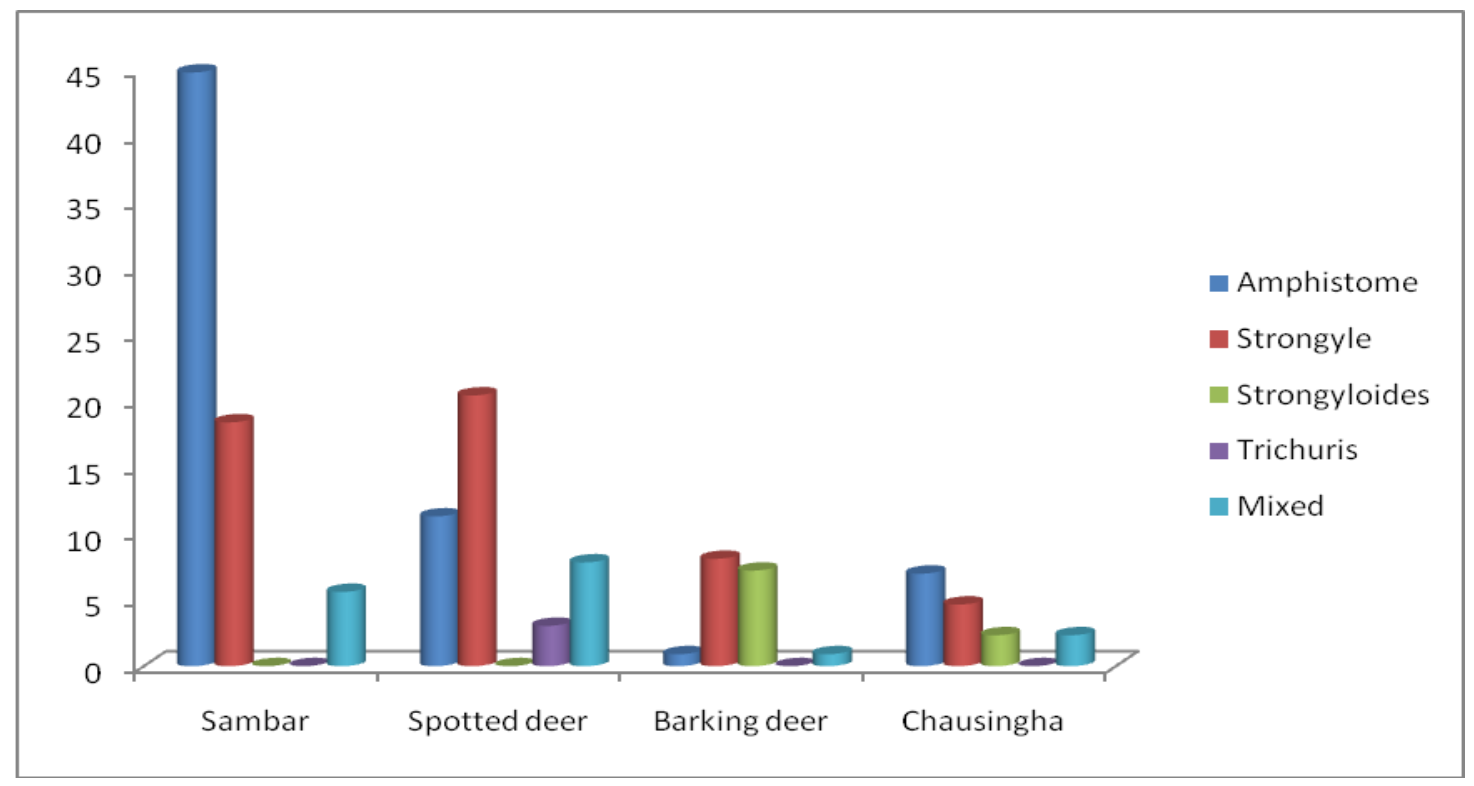


In Van Vihar National Park, Bhopal Singh et al., (2009), noted the highest prevalence for Strongyles (26.15\%) followed by Strongyloides sp. (7.13\%), amphistomes (1.98\%) and Trichuris sp. (1.84\%) in free ranging herbivores. The predominance of amphistomes in our study could be due to evidence of presence of snail intermediate host i.e. aquatic snails (Indoplanorbis spp and Lymnea spp) in the fodder farm at the back side of the Safari, from where fodder is supplied to the animals.

As per our research, the overall prevalence of parasites was higher in the rainy season which supports the findings of Modi et al., (1997) in Bihar, Dharmarajan et al., (2005) in South India and Singh et al., (2009) in Bhopal detecting a higher prevalence of parasites in the rainy season in herbivores. The increase can be attributed to higher humidity and favourable condition with increased larval survival and increase in intermediate host population. Jadhav et al., (2010) and Hussain et al., (2002) have reported higher prevalence of gastro-intestinal parasites in rainy season which agrees with our findings in spotted deer.

The study concluded that trematodes and nematodes, though of low intensity were prevalent in the herbivore safari of Nandankanan Zoological Park. The existing infection can be controlled by adopting suitable anthelmintic therapy while ensuring proper administration of drug, along with proper management practices. Elimination of snail intermediate host could also help in reducing the parasitic burden on the animals.

\section{Acknowledgement}

The authors are grateful to Sri Sisir Kumar Acharya, Director, Nandankanan Zoological Park for his permission and providing all facilities from the zoo and Dr. Sarat Sahu,
V.A.S., Nandankanan Zoological Park, for his kind support, helpful suggestion and encouragement during the research work.

\section{References}

Ananda, K.J., S. Chandrasekhar, N. Yeshaswari, A.K. Ramesh and $\mathrm{M}$. Devraj. 2012. Proceedings of XXII National Congress of IAAVP and National Symposium on Integrated research Approaches in Veterinary Parasitology from Basic to Molecular Technique, March 15-17, 2012, 28.

Atanaskova, E., Z. Kochevski, J. Stefanovska and G. Nikolovski. 2011. Endoparasites in wild animals at the zoological garden in Skopje, Macedonia, Journal of Threatened Taxa, 3(7): 1955-1958.

Aviruppola, A.J.M.K., R.P.V.J. Rajapakse and R.S. Rajakaruna. 2016. Coprological survey of gastrointestinal parasites of mammals in Dehiwala National Zoological Gardens, Sri Lanka, Ceylon Journal of Science, 45(1): 83-96.

Banerjee, P.S., R. Garg, C.L. Yadav and H. Ram.2005. Parasitic infections in some wild animals of Uttaranchal, Indian Journal of Animal Sciences, 75(2): 206-208.

Bante, S., R.K. Bagherwal and V. Agrawal.2013. Prevalence of Helminth Parasites in Wild Animals of Zoological Park at Indore, Indian Veterinary Journal, 90(7): 84- 86.

Barmon, B.C., N. Begum, S.S. Labony, U.K. Kundu, A.R. Dey and T.R. Dey.2014. Study of gastrointestinal parasites of deer at char kukri mukri in Bhola district,Bangladesh Journal of Veterinary Medicine, 12 (1): 27-33.

Borghare, A.T., V.P. Bagde, A.D. Jaulkar, D.D. Katre, P.D Jumde, D.K. Maske and G.N. Bhangale. 2009. Incidence of 
gastrointestinal helminthiasis in captive deers at Nagpur, Veterinary World, 2(9): 337-338.

Chhabra, M.B. and K.M.L. Pathak.2013. An overview of parasites of wildlife in India. I. Herbivores, primates and reptiles, Indian Journal of Animal Sciences, 83(5): 463-472.

Cossio-Bayugar, A., E. Romero, S. Gallina, G. Suzan, and S. Ibanez-Bernal.2015. Variation of gastro-intestinal parasites in mule deer and cattle in Mapimi Biosphere Reserve, Mexico, Southwestern Naturalist, 60(2/3): 180185.

Dharmarajan, G., M. Raman, and M.C. John.2005. Effect of season on helminth loads of wild herbivores and cattle in the Mudumalai wildlife sanctuary, Southern India, Zoo's Print Journal, 20(2): 1766-1769.

Gorman, T.R., V. Riveros, H.A. Alcaino, D.R. Salas and E.R. Thiermann. 1986. Helminthiasis and toxoplasmosis among exotic mammals at the Santiago National Zoo, Journal of the American Veterinary Medical Association, 189(9): 1068-1070.

Gupta, A., A.K. Dixiit, P.Dixit, C. Mahajan and A.B. Shrivastava.2011. Incidence of gastro-intestinal parasites in wild ruminants around Jabalpur, India, Journal of Threatened Taxa, 3(11): 2226-2228.

Hussain, K., N.P. Dakshinkar, A.M. Rode, M.D. Kothekar and D.K. Maske. 2002. Prevalence of helminthic infection in axis deer at Nagpur. Indian Vet. J. 79(12): 87-88.

Islam, S.K.M.A., S. Ahmed, M.A. Hoque, M.A. Alim and M.M. Hassan.2003. Gastrointestinal parasites of captive deer and their response to selected anthelmintics. Bangladesh Veterinary Journal, 37: 63-66.

Jadhav, P., K. Jadhav, P. Chavan, B.
Baviskar, and D.K. Maske.2010. Seasonal variation in prevalence of helminthic infection in the captive spotted deer at Nagpur, Zoo's Print Journal, XXV(5): 18.

Jaiswal, A., A. Srivastava, V.Sudan, R. Singh, D.Shanker and R. Parashar 2014. Prevalence of endoparasitic infections in wild cervids of Army Golf Course, Mathura, Journal of Parasitic Diseases, 38(4):358-360.

Kanungo, S., A.Das, M. Das Gupta, and Shakif-ul-Azam. 2010. Prevalence of gastro-intestinal helminthiasis in captive deer of Bangladesh, Wayamba Journal of Animal Science, 578X (1288421279): 42-45.

Kafil, H., D. B Sarode, N. P. Dakshinkar, A. M. Rode, M. D. Kothekar and D. K. Maske. 2002. Prevalence of helminths infection in axis deer from Nagpur, India, Indian Veterinary Journal, 7: 1313-1314.

Kashid, K.P., G.B. Shrikhande, and G.R. Bhojne.2003. Incidence of gastrointestinal helminthes in captive wild animals at different locations, Zoo's print journal, 18(3): 1053-1054.

Khan, I.A., J.D Shaikh, M.K. Kale, V.D. Jadhav, L.B. Dama and Ragade Vinod.2014. Prevalence of gastrointestinal parasites in captive animals of Siddhartha garden zoo at Aurangabad city, Maharashtra, India, Trends in Parasitology Research, 3(1): 12-16.

Mandal P., M.G. Jayathangaraj, L. John, B.R. Latha and M. Raman.2002. Prevalence of helminthic infection in free ranging chital (Axis axis) at Mudumalai Wildlife Sanctuary, Tamil Nadu. Proceedings of the XIII National Congress of Veterinary Parasitology, (February. 14-16), Kolkata.

Modi GS, B.N. Prasad, B.K. Sinha.1997. Seasonal effect on prevalence of 
parasitic zoonotic diseases among zoo animals of Bihar. Zoos Print 12: 8-11.

Mohan M. and Coumarane K. 2007. Endoparasitic infection of Spotted Deer (Axis axis) in Puducherry. Zoo's Print; 22 (12). P.2952.

Singh P., M.P. Gupta, L.D. Singla, S. Sharma, B.S. Sandhu and D.R.Sharma.2006. Parasitic infections in wild herbivores in the Mahendra Choudhury zoological park, Chhatabir, Punjab, Zoo's print journal, 21 (11): 2459246.

Singh S., A.B. Shrivastav and R.K. Sharma. 2009. The epidemiology of gastrointestinal parasitism and body condition in free-ranging herbivores, Journal of Threatened Taxa, 1(10): 535-537.

Rahman S.M., A.R. Dey, U.K. Kundu and N.
Begum (2014). Investigation of gastrointestinal parasites of herbivores at Dhaka National Zoological Garden of Bangladesh, Journal of Bangladesh Agriculture University, 12 (1): 79-85.

Sahoo N., P.K. Roy, A. Das, R.K. Samantaray, M. Dehuri and K.M.N. Bharti (2009) Gastrointestinal helminthic infection in animals of Nandankanan Zoological Park, Journal of Veterinary Parasitology, 23 (1): 95-96.

Thawait Virendra Kumar and S.K. Maiti (2015). Prevalence of gastro-intestinal parasites in captive wild animals of Kanan Pandari Zoo, Bilaspur, Journal of Animal Research, 5 (1): 199-202.

\section{How to cite this article:}

Das, S., M. Dehuri, M.R. Panda, N. Sahoo, B.N. Mohanty and Mahapatra, T. 2018. Gastrointestinal Helminthic Infection in Herbivore Safari at Nandankanan Zoological Park. Int.J.Curr.Microbiol.App.Sci. 7(08): 1034-1039. doi: https://doi.org/10.20546/ijcmas.2018.708.116 